\title{
APONTAMENTOS INICIAIS SOBRE A PUBLICIDADE COLABORATIVA: UMA COLABORAÇÃO PARA A PESQUISA
}

LÚCIO SIQUEIRA AMARAL FILHO ESPM Sul Porto Alegre, Rio Grande do Sul, Brasil

E-mail: lucio@lucioamaral.com.br 
APONTAMENTOS INICIAIS SOBRE A PUBLICIDADE COLABORATIVA: UMA COLABORAÇÃO PARA A PESQUISA

Resumo: Uma das atuais fontes de informação para as marcas reside nos usuários da internet. Isso se deve, em grande parte, pela propagação de ferramentas de produção e compartilhamento de conteúdos advindos com a web 2.0 e com a cultura do "do it yourself". Com base nisso, o presente trabalho pretende apresentar alguns elementos que possam ter contribuído para a ascensão do fenômeno da publicidade colaborativa, além de colaborar com a pesquisa desse fenômeno, que ainda se encontra em uma fase inicial.

Palavras-chave: Publicidade colaborativa, publicidade amadora, web 2.0.

NOTAS INICIALES SOBRE LA PUBLICIDAD COLABORATIVA: UNA COLABORACIÓN PARA LA INVESTIGACIÓN

Resumen: Una de las actuales fuentes de información para las marcas radica en los usuarios de internet. Esto se debe, en gran parte, por la difusión de las herramientas de producción y distribución de contenidos que llegan a la web 2.0 y la cultura del "do it yourself". En base a esto, este artículo presenta algunos elementos que pueden haber contribuido al aumento del fenómeno de la publicidad colaborativa, además de apoyar la investigación de este fenómeno, que todavía está en una etapa temprana.

Palabras clave: Publicidad colaborativa, publicidad amateur, web 2.0

INITIAL NOTES OF THE COLLABORATIVE ADVERTISING: A COLLABORATION FOR RESEARCH

Abstract: One of the current sources of information for brands lies in internet users. This is due, in large part, by the spread of production and sharing of content tools coming to web 2.0 and the "do it yourself" culture. Based on this, this paper presents some elements that may have contributed to the rise of the collaborative advertising phenomenon, in addition to supporting the research of this phenomenon, which is still at an early stage.

Keywords: Collaborative advertising, amateur advertising, web 2.0. 


\section{INTRODUÇÃO}

O trabalho realizado pelo publicitário vem se transformando ao longo dos últimos anos, seja em função dos avanços tecnológicos, sociais ou econômicos, seja pelas próprias "leis de mercado", que fazem necessário estar reinventando-se diariamente, a fim de manter o relacionamento com os clientes e conquistar novos clientes. No presente trabalho dois desses fatores terão maior interesse: os tecnológicos e os sociais. Neste sentido, ambos estão intrinsecamente ligados, visto que os avanços das tecnologias da comunicação e da informação permitiram que novas relações sociais fossem criadas, agrupando pessoas em torno de interesses comuns (LEMOS, 2004).

A partir desses avanços, a criação e o compartilhamento de conteúdos tiveram um aumento muito considerável, dada as possibilidades advindas com as ferramentas proporcionadas pela web 2.0. Passa-se de um modelo do tipo um-todos para um modelo todos-todos (LEMOS, 2004), em que todos os usuários podem interagir uns com os outros, criando e compartilhando conteúdos, sem estar mais na dependência de poucos polos de emissão.

\section{PUBLICIDADE E ECONOMIA COLABORATIVA}

A partir da exponencialização dos processos de produção e distribuição, advindos com a democratização das ferramentas propiciadas pela web 2.0, cresceu também a colaboração na rede. Empresas e marcas passaram a contar com um maior auxílio por parte dos consumidores, que agora poderiam manifestar seus contentamentos ou descontentamentos para com elas. A busca e consequente encontro dessas informações e conteúdos tornaram-se mais fáceis, o que ocasionou uma nova reconfiguração econômica da sociedade.

No campo da publicidade não ocorre de uma forma diferente. Empresas apropriam-se dos cada vez mais abundantes canais de comunicação com seus consumidores para entendê-los, seus sentimentos e seus desejos. Marcas lançam concursos onde o público envia vídeos e fotos e os mais votados farão parte da sua próxima campanha publicitária. Os próprios usuários da rede, por sua livre e espontânea vontade, criam peças publicitárias para manifestarem sua idolatria ou seu repúdio para com determinados produtos ou serviços. Agências online são criadas, a fim de contar com a colaboração de criativos de todo o tipo, conectados virtualmente, apropriando-se de mensagens publicitárias para transformá-las em conteúdos colaborativos. A colaboração, agora, faz parte de estratégias das empresas, com o intuito de ge- 
rar lucros monetários, não mais informacionais e de conteúdo, como antes.

Essa nova era de reconfiguração tecnológica e demográfica na economia e no mundo é chamada por Tapscott $\&$ Williams de Wikinomics.

[...] essa nova participação atingiu um ápice no qual novas formas de colaboração em massa estão mudando a maneira como bens e serviços são inventados, produzidos, comercializados e distribuídos globalmente. Essa mudança apresenta oportunidades de longo alcance para todas as empresas e pessoas que se conectam. (TAPSCOTT \& WILLIAMS, 2007, p. 20)

O termo wikinomics é uma aglutinação das palavras wiki e economics, esta sendo economia e originária do inglês. Wiki é um software que possibilita alterações pelos usuários do conteúdo de páginas na internet que, por sua vez, deriva da expressão havaiana wikiwiki, que significa super rápido. A primeira utilização do termo foi como wikiwikiweb, por Ward Cunningham em 1995 (ZAIDAN \& BAX, 2010). Conforme Cunningham (2010), o termo wiki tornou-se muito mais do que ele próprio imaginaria. Para ele, seus princípios consistem em ser simples, aberto, incremental, orgânico, mundano, universal, evidente, unificado, preciso, tolerante, observável e convergente.

O responsável por disponibilizar ferramentas que permitem a colaboração, a criação de valor e a competição para todos é o crescimento das tecnologias da informação (TAPSCOTT \& WILLIAMS, 2007). Com elas, as pessoas estão livres para inovar e criar valores nos setores da economia. O maior exemplo disso pode ser dado pela Wikipedia', uma enciclopédia digital livre em que qualquer usuário pode incluir, excluir e editar o conteúdo. Uma enciclopédia feita pelos e para o usuário, colaborativa, que não pertence a ninguém, mas que também é de todos.

Conforme os autores, para as empresas terem sucesso elas precisam adotar um novo modelo de gestão colaborativa, incentivando a colaboração ativa de seus funcionários e clientes.

Um novo tipo de empresa está surgindo - uma empresa que abre as suas portas para o mundo, inova em conjunto com todos (sobretudo os clientes), compartilha recursos que antes eram guardados a sete chaves, utiliza o poder da colaboração em massa e

1 Disponível em http://www.wikipedia.org. Acesso: 20 maio de 2013. 
se comporta não como uma multinacional, mas como algo novo: uma firma verdadeiramente global. (TAPSCOTT \& WILLIAMS, 2007, p. 31)

Assim, ações em um mercado global permitirão que novas ideias e tecnologias se tornem acessíveis. Para isso, as empresas terão que relacionar-se com o mundo, participando das mudanças nos processos globais, além de ter uma capacidade global, tanto de mão-de-obra quanto nas tecnologias da informação, a fim de estimular a colaboração de seus parceiros internos e externos.

O mesmo ocorre com a publicidade. Ela deve estar aberta ao conhecimento dos consumidores, a trocas entre os públicos que criam e recebem as mensagens. Abertura essa possibilitada pelas ferramentas da web 2.0, que permitem aos publicitários entender o que seu público-alvo de seja e como deseja.

\section{PUBLICIDADE E CULTURA PARTICIPATIVA}

Na cultura participativa o consumidor não absorve mais os conteúdos e as informações de forma passiva, ele escolhe o que, como e onde consome os meios de comunicação. Ele passa a ser o porta-voz dos produtos, participando constantemente em discussões em comunidades, seja para defender os produtores amadores ou para gerar novas demandas. O consumidor é, acima de tudo, alguém que pode gritar e ser ouvido pelas marcas.

Essa possibilidade ofertada aos cidadãos comuns deve-se, basicamente, à democratização das ferramentas de produção e distribuição de conteúdo, o que reduziu os custos operacionais e faz com que cada vez mais produtos e serviços possam ser disponibilizados para os consumidores. $O$ impacto desse novo modelo de negócio recai sobremaneira nas indústrias digitais e de entretenimento, onde se formam novos e pequenos nichos de mercado que agrupam pessoas em torno de interesses comuns. Robert Kozinets, citado por Jenkins (2008), considera as comunidades de consumo online

locais onde grupos de consumidores com interesses semelhantes buscam e trocam, de forma ativa, informações sobre preços, qualidade, fabricantes, revendedores, ética da empresa, história da empresa, história do produto e outras características relacionadas ao consumo. [...] A participação das comunidades não apenas reafirma a preferência por uma marca, mas também permite a esses grupos fazer suas próprias exigências às empresas. (JENKINS, 2008, p. 117) 
Se no século XIX a produção cultural era no nível popular, onde as habilidades artísticas eram passadas de pai para filho, no século XX as fronteiras ente o amador e o profissional eram imensas, devido, sobretudo aos altos investimentos e conhecimentos tecnológicos. Por sua vez, agora se vive uma cultura onde as manifestações populares emergem de uma maneira nunca antes vivenciada, dando espaço aos produtores amadores (JENKINS, 2008). Espaço que pode ser encontrado principalmente nas comunidades virtuais, onde os conteúdos tem uma livre e constante circulação.

Contudo, Jenkins (2008) afirma que o poder da participação é temido por alguns e acolhido por outros, uma vez que não há garantias de sua meIhor utilização que o fazem os estados e as organizações com seus poderes. O que está sendo feito agora são experimentações das melhores formas de utilização dessa cultura participativa, definindo-se seus códigos e contratos, como grupos diferentes podem trabalhar em conjunto. O início se dá na cultura popular por ser ela quem apresenta os menores riscos e as menores consequências econômicas e sociais. Após essa experiência toda trazer resultados positivos e entendimento de seu funcionamento, é que poderá ser aplicada na educação, política, trabalho, economia. A participação, esse novo modelo de produção cultural, "é vista como uma parte normal da operação da mídia, e os debates atuais giram em torno das condições dessa participação" (JENKINS, 2008, p. 314).

A participação dos consumidores pode ser entendida a partir do equilíbrio entre o fascínio e a frustração. O fascínio pelas tecnologias digitais da comunicação e da informação, por ser ouvido e visto por empresas e por um alto número de pessoas, o fascínio por poder expor a opinião e as habilidades. A frustração com empresa, marcas, pessoas e governos. A junção desse fascínio e dessa frustração faz com que os consumidores criem comunidades para mostrar sua insatisfação em relação a um produto, a criar vídeos e postá-los em sites de hospedagem de vídeos.

O interessante na cultura participativa é a forma vertical como as ideias se movimentam. Elas podem se espalhar de cima para baixo, surgindo da mídia comercial e sendo absorvida e espalhada pela cultura; mas também podem sofrer o processo contrário, de baixo para cima, quando a cultura participativa é absorvida e comercializada pela grande mídia. Aqui, “o poder da mídia alternativa é que ela diversifica; o poder da mídia de radiodifusão é que ela amplifica" (JENKINS, 2008, p. 326).

Manovich (2003) vê a atual cultura através de três processos-chave, ou 
três tipos de remix: o primeiro, o pós-modernismo, remixa conteúdos e formas culturais anteriores; o segundo, o da globalização, faz remix das tradicionais culturas globais; e o terceiro tipo de remix é o das novas mídias, que é a remixagem entre a cultura e as tecnologias digitais.

É na fusão entre a cultura e as tecnologias digitais que reside a cultura participativa que pode ser vista por toda a sociedade. O fascínio pelas tecnologias digitais e sua facilidade de acesso que proporciona que conteúdos criados por amadores sejam criados e distribuídos pela rede. A ausência de obstáculos para o acesso a softwares e seu consequente entendimento facilitado possibilitam a criação, distribuição e participação das pessoas. Hoje a sociedade está centrada no software.

Motores de busca, sistemas de recomendação, aplicativos de mapeamento, ferramentas de blogs e leilões, clientes de mensagens instantâneas, e, claro, plataformas que permitem outros a escreverem novos programas - Facebook, Windows, Unix, Android - estão no centro da economia global, cultura, vida social e, cada vez mais, na política. (MANOVICH, 2008, p. 3) $)^{2}$

\section{PUBLICIDADE VIRAL}

O fato de fazer comentários e emitir opiniões é uma característica intrínseca do ser humano, sempre querendo expressar o seu gosto por determinadas coisas e assuntos, falando se são bons ou ruins para outras pessoas, aconselhando ou desaconselhando. A propaganda boca-a-boca acontece quando esses comentários se referem a produtos, sendo ela uma prática constante desde o aparecimento das opções de escolha. No começo ela era um fenômeno espontâneo que surgia em meio a uma conversa informal, quando algum dos participantes tecia comentários, positivos ou negativos, a respeito de um determinado produto. Essa opinião era tida como de credibilidade pelos ouvintes, pois quem estava opinando provavelmente teria experimentado o produto e saberia o que estava falando. Até hoje esse fenômeno ocorre, afinal, todos já ouviram ou fizeram comentários para outras pessoas a respeito de algum produto, independente do teor da opinião.

2 Tradução livre do autor para "Search engines, recommendation systems, mapping applications, blog tools, auction tools, instant messaging clients, and, of course, platforms which allow others to write new software - Facebook, Windows, Unix, Android - are in the center of the global economy, culture, social life, and, increasingly, politics". 
Com o passar do tempo a propaganda boca-a-boca adquiriu mais importância nas estratégias de marketing e comunicação das empresas, passando a ser utilizada em função da experiência de consumidores com os produtos, atraindo a atenção para eles. A partir de uma experiência bem sucedida e boa com o produto, o cliente cita os seus benefícios, fazendo a indicação para outras pessoas. Essa forma de influência é semelhante à dos formadores de opinião, mas não com a mesma credibilidade massiva deles, é uma credibilidade baseada no contato e relacionamento das pessoas, onde uma vai comunicando para a próxima, e assim continua sucessivamente. Mas não é apenas com base em experiências que essa estratégia funciona, ela também emprega todos os tipos de comentários sobre os produtos, utilizando o consumidor como forma de disseminação das mensagens.

O marketing viral faz uso da internet como meio de propagação da mensagem. Para Felinto (2007, p. 3), "o termo define uma estratégia de comunicação fundada na idéia de explorar redes sociais pré-existentes para produzir aumentos exponenciais de propagação de uma marca ou conceito, de forma similar ao que sucede numa epidemia." Isso significa que a viralização não é um fato atual. Antes da existência da web 2.0 já era possível viralizar mensagens, através de e-mails, salas de bate-papo e programas de mensagens instantâneas como o mIRC e o ICQ.

O que ocorre agora é a exponencialização da propagação de todo tipo de mensagem pelo que distingue a web 2.0 da sua geração anterior, seu poder de compartilhamento e publicação. Dessa forma, através de widgets's, os usuários podem publicar e compartilhar vídeos em seus blogs e redes sociais como Orkut, Facebook e MySpace, sites de compartilhamento de vídeos como YouTube, Vimeo e Dailymotion, além de utilizar todas as ferramentas disponíveis de blogs, microblogs, compartilhamento, publicação e redes sociais para disponibilizar endereços de vídeos que se deseja viralizar.

Exemplos de vídeos viralizados podem ser encontrados facilmente por toda a parte da rede: Numa Numa Dance é um vídeo em que um rapaz dança na frente da webcam com fones nos ouvidos, lutubiu, onde uma empregada doméstica tenta e não consegue falar YouTube, Sanduíche-iche, quando uma entrevistada se confunde com o delay da transmissão ao vivo, Chocolate Rain, vídeo de um garoto de camiseta branca em um estúdio de gravação que canta uma música com sua voz grave.

3 Widgets são elementos gráficos que representam aplicações interativas nos sites da web, e fazem com que o usuário consiga executar ações as quais o aplicativo se destina. 
Todos esses são vídeos feitos sem interesses na sua viralização, diferente do vídeo Dove Evolution. Ele é o making-of da produção de uma modelo para uma campanha publicitária, e foi criado apenas para ser veiculado na internet, com a intenção de ser viralizado na rede. Foi o primeiro vídeo a ganhar o GP Viral na categoria Cyber, criada em 2007 no Festival de Cannes.



Figura 1: Dove Evolution

Fonte: Disponível em http://goo.gl/wuCS'

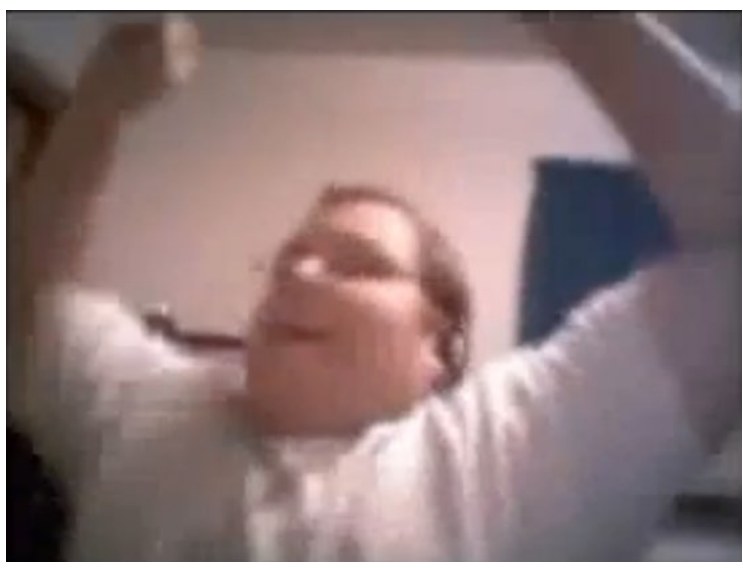

Figura 2: Numa Numa Dance Fonte: Disponível em http://goo.gl/S1U2 ${ }^{2}$

\section{USER GENERATED CONTENT - UGC}

User generated content, segundo o IAB, é

também conhecido como mídia gerada pelo consumidor (consumer generated media - CGM), referindo-se a qualquer material criado e carregado para a internet por usuários que não são profissionais da mídia, como um comentário deixado na Amazon.com, um vídeo com qualidade profissional enviado para o YouTube, ou o perfil de um estudante no Facebook ${ }^{4}$. (IAB, 2008, p. 1)

Manovich (2008) afirma que o ano de 2005 pode ser considerado como o marco na revolução da mídia do consumidor. Segundo ele, nesse ano houve uma explosão de postagens nos blogs com fotos e vídeos, o YouTube entrou no ar e o Flickr foi comprado pelo Yahoo, além do termo user generated content ter virado uma expressão comumente referenciada. Manovich ainda relaciona uma nova situação cultural iniciada no início dos anos 2000 ao crescimento exponencial do número de profissionais e não-profissio-

4 Tradução livre do autor para "also known as consumer-generated media (CGM), refers to any material created and uploaded to the Internet by non-media professionals, whether it's a comment left on Amazon.com, a professional-quality video uploaded to YouTube, or a student's profi le on Facebook" (IAB, 2008, p. 1). 
nais produtores de mídia. Com essa amplificação, milhões de pessoas estão constantemente criando e compartilhando conteúdos culturais, tais como vídeos, fotos, comentários, discussões, entre tantos outros. São os chamados "profissionais da cultura", que participam em produções e discussões globais devido à facilidade de acesso a ideias, informações e ferramentas disponibilizadas pela web 2.0.

Nesse mesmo sentido, Vickery e Wunsch-Vincent (2007) classificam o que chamam de conteúdo criado pelo usuário como sendo um conteúdo disponibilizado na internet, reflexo de um certo esforço criativo e com produção fora de práticas e rotinas profissionais. Para eles, a maioria desse conteúdo é feita sem a expectativa de haver lucro ou remuneração. As motivações seriam a conexão com os pares, autoexpressão e aquisição de fama, notoriedade e prestígio.

As tradicionais formas de publicação, que incluem a televisão, rádio e mídias impressas, dependem de gatekeepers, detentores das chaves dos "portões" responsáveis por deixar as informações fluírem. Ou seja, tradicionalmente existem filtros que selecionam o que e como deve ser publicado na mídia, reduzindo a quantidade de conteúdo disponível às pessoas. Por sua vez, no conteúdo gerado pelo usuário os gatekeepers desaparecem, uma vez que os usuários criam e postam seus conteúdos diretamente em plataformas de UGC, como blogs, sites de compartilhamento de vídeos e fotos, etc. Assim, "os usuários selecionam o que funciona e não funciona, por exemplo, através de recomendação e avaliação, possivelmente levando ao reconhecimento criadores que talvez não fossem selecionados pelos editores tradicionais de mídia"" (VICKERY \& WUNSCH-VINCENT, 2007, p. 10).

Textos, fotos e imagens, música e áudio e vídeo e filme são os quatro tipos de UGC propostos por Vickery e Wunsch-Vincent (2007). Esses conteúdos são hospedados em serviços que oferecem espaço para que eles sejam acessados, as plataformas de UGC, as quais podem ser blogs, wikis (ou outra ferramenta colaborativa textual), podcasting, sites de redes sociais, serviços de compartilhamento de favoritos e mundos virtuais em jogos online.

5 Para fins de facilidade, adotar-se-á aqui UGC como abreviação de conteúdo gerado pelo usuário.

6 Tradução livre do autor para "users select what does e does not work, for example, through recommending and rating, possibly leading to recognition of creators who would not be selected by tradicional media publishers". 


\section{CROWDSOURCING}

O termo crowdsourcing foi utilizado pela primeira vez por Jeff Howe, editor da Revista Wired. Uma ligação entre as palavras da língua inglesa crowd (multidão, grupo, povo) e sourcing (fonte), significa uma fonte que tem origem em grupos de pessoas. Diferente de outsourcing, em que uma pessoa é buscada fora da empresa para realizar determinado trabalho, ou seja, uma terceirização.

Outsourcing é quando se contrata alguém para executar um serviço e ele o faz e isso é o fim do relacionamento. Isso não é muito diferente da forma de trabalho que vem sido trabalhada ao longo dos tempos. Estamos falando de trazer pessoas de fora e envolvê-las neste amplo processo criativo colaborativo. Isso é um paradigma completamente novo. (HUSTON, apud HOWE, 2006, p. 5)

O crowdsourcing pode ser considerado um resultado proporcionado pela democratização das ferramentas de criação e publicação advindas com a web 2.0, uma plataforma universal de circulação de mídias não-profissionais, conforme Manovich (2008), que ainda afirma que a transformação dos consumidores de mídias em produtores de mídias, aliados à queda dos preços, ao aumento das capacidades dos aparelhos eletrônicos (máquinas fotográficas digitais, notebooks, celulares) e às novas plataformas de mídias sociais criaram uma nova e heterogênea dinâmica das mídias. Um universo baseado em redes de colaboração, compartilhamento, misturas, "blogging", "reblogging" e muito mais à disposição de usuários, marcas e empresas.

Howe (2008) afirma que a prática do crowdsourcing foi reinterpretada e modificada, sendo aplicada por empresas até organizações sem fins lucrativos. Whitla (2009) enfatiza a sua utilização por empresas de marketing como uma forma das pessoas projetarem e criarem seus próprios conteúdos e produtos. Para o autor, o crowdsourcing pode ser visto como uma prática que mistura o trabalho e o lazer, pondo em causa a capacidade de incentivar a ação em prol de um acordo de trabalho mais flexível, prazeroso e autônomo.

7 Tradução livre do autor para "Outsourcing is when I hire someone to perform a service and they do it and that's the end of the relationship. That's not much different from the way employment has worked throughout the ages. We're talking about bringing people in from outside and involving them in this broadly creative, collaborative process. That's a whole new paradigm." 
Conforme Howe (2008), os participantes do crowdsourcing, a princípio, não são motivados a participar por dinheiro, além de estarem doando suas horas de lazer para a causa. Isto é, eles contribuem com sua capacidade excedente, ou "ciclos de reposição", para fazer alguma coisa que tem adoração em fazer. Para ele, pessoas que possuem habilidades muito diversas e experiência profissional estão empenhadas em participar. Ainda, é preciso uma maior flexibilidade na definição do termo amador, uma vez que com a emergência do crowdsourcing amadores estão competindo com igualdade de forças com profissionais, desde o campo da programação computacional, até o jornalismo e as ciências. A energia e a devoção com que o amador aplica nas tarefas são o combustível para a máquina do crowdsourcing, pois "precisamos entender que o amadorismo é menos uma designação do que um fantasmas" (HOWE, 2008, p. 28). O autor cita a designação Pro-Am, criada por Charles Leadbeater e Paul Miller, que refere-se a amadores que trabalham em níveis profissionais.

Um princípio básico fundamentaliza o crowdsourcing: a terceirização do trabalho está baseada em convites realizados em/a partir de comunidades online. Neles são detalhadas tarefas ou problemas, e usuários ou grupos submetem propostas criativas como respostas para resolvê-los.

Quatro desdobramentos criaram um terreno fértil no qual o crowdsourcing poderia emergir. A ascensão da classe amadora foi acompanhada da emergência de um modo de produção - software de código aberto - que fornece inspiração e sentido prático. A proliferação da Internet e das ferramentas baratas deram aos consumidores um poder antes restrito a empresas dotadas de grandes recursos de capital. Mas foi a evolução das comunidades online - com a habilidade de organizar eficazmente as pessoas em unidades economicamente produtivas - que transformou os primeiros três fenômenos em uma força irreversível. (HOWE, 2008, p. 99)

8 Tradução livre do autor para "we need to understand that amateurism is less a designation than it is a spectrum."

9 Tradução livre do autor para "Four developments created a fertile ground in which crowdsourcing emerge. The rise of the amateur class was accompanied by the emergence of a mode of production - open source software - that provides inspiration and practical direction. The proliferation of the Internet and cheap tools gave consumers a power once restricted to companies endowed with vast capital resources. But it was the evolution of online communities - with their hability to efficiently organize people into economically productive units - that transformed the first three phenomena into a irrevocable force." 
Assim, crowdsourcing é um modelo pra resolução de problemas que são distribuídos pela internet, onde vários usuários participam com ideias criativas. É a internet que torna o fenômeno do crowdsourcing muito mais vasto, em quase todas as instâncias, o que faz com que não seja qualquer morador do planeta que possa participar dele: precisa ser usuário da internet. Para isso, Howe (2008) utiliza um sinônimo para explicar melhor e facilitar o entendimento desse fenômeno: bilhão, pois existe um pouco mais de um biIhão de usuários da internet no mundo, e todas são potenciais participantes e colaboradores do crowndsourcing.

\section{ALGUNS EXEMPLOS}

A colaboração e a participação das pessoas na criação de campanhas publicitárias não é uma coisa recente, que existe apenas como consequência da disseminação da internet. Elas já ocorrem desde antes do fenômeno participativo advindo com a web 2.0. No final da década de 90 a marca de roupas gaúcha Gang já contava com a colaboração do seu público em sua comunicação. Com o slogan "A loja que te entende", a marca investiu no entendimento de seu público, a ponto de pedir sua colaboração para criação de suas campanhas publicitárias. Através de anúncios e cartazes, as pessoas eram convidadas e criar campanhas para as coleções de verão ou inverno, enviando as sugestões para a empresa. As opções escolhidas eram colocadas em prática, através de sua agência de publicidade. De acordo com a empresa (2010), essas campanhas são uma forma que os adolescentes encontram para dizer o que querem, mas nem sempre encontram onde dizer. Ainda para ela, "o slogan "A loja que te entende” não é apenas uma forma bacana de assinar seus anúncios; é, sim, a confirmação do compromisso de dar voz ao seu público". Dessa maneira, a marca consegue entender seu público, tendo como referência a imensa quantidade de propostas de campanhas que recebe com a colaboração dos consumidores, o que realmente leva de encontro ao seu slogan e à premissa de ser uma loja que entende o seu público.

No ano de 2005, a Procter \& Gamble publicou na internet um site onde os usuários poderiam editar cenas já filmadas de uma dançarina, com o intuito de criar uma história em vídeo. O site, chamado When Shes's Hot, promovia uma de suas marcas de desodorante e os usuários tinham a liberdade de criar quantos vídeos quisessem. 
Em 2006, o adolescente americano Tyson Ibele, na época com 18 anos, criou um vídeo em um aparelho de som transforma-se em uma televisão, esta em um notebook, que então se transmuta em uma câmera fotográfica digital, que, por sua vez, vira um vídeo game portátil, todos da marca Sony. Por livre e espontânea vontade o jovem americano produziu o comercial e mostrou-o a um amigo, que resolveu colocá-lo na internet. Foi o necessário para a criação de uma celebridade, sendo que internautas americanos chegaram a eleger o vídeo como o melhor comercial da Sony até aquele momento. Por sua vez, a Sony declarou reconhecimento à criação de Tyson, mas não utilizou seu vídeo em campanhas publicitárias.



Figura 3: Sequência do comercial de Tyson Ibele para a Sony

Fonte: Disponível em http://goo.gl/ynhT8 ${ }^{10}$

No mesmo ano, a Nokia, empresa finlandesa de aparelhos celulares, instalou um quiosque no aeroporto de Lisboa, onde as pessoas que paravam na frente de um aparelho celular com câmera eram fotografadas. Com o consentimento das pessoas, as fotos acabavam fazendo parte de um outdoor publicitário.

Mas nem sempre os resultados acontecem de acordo com o planejado. Um exemplo é a campanha Make Your Own Tahoe Commercial, da General Motors dos Estados Unidos, para um de seus modelos utilitários. Foi criado um hotsite com vídeos do Tahoe, e os usuários colaboravam inserindo textos nele. O problema residiu na falta de filtragem dos vídeos, sendo que inúmeros deles traziam protestos a respeito da influência da marca no aquecimento global.

Modelo parecido com o da General Motors foi adotado no Brasil, em 2007, pela cerveja Skol. Em um hotsite especialmente criado para suas campanhas, a Skol oferece um vídeo em que dois amigos estão no banheiro. O consumidor é convidado a criar legendas com possíveis conversas entre eles, e então enviar para seus amigos. Alguns temas já foram disponibilizados, como cue-

10 Acesso em: 20 maio 2013. 
ca, masoquismo e cola, mas fica a abertura para a criatividade dos consumidores em criar seus textos e distribuí-los para sua rede de contatos, que, por sua vez, pode reencaminhar, ou até mesmo criar uma nova conversa e enviar para sua rede, criando um processo progressivo sem um possível fim.

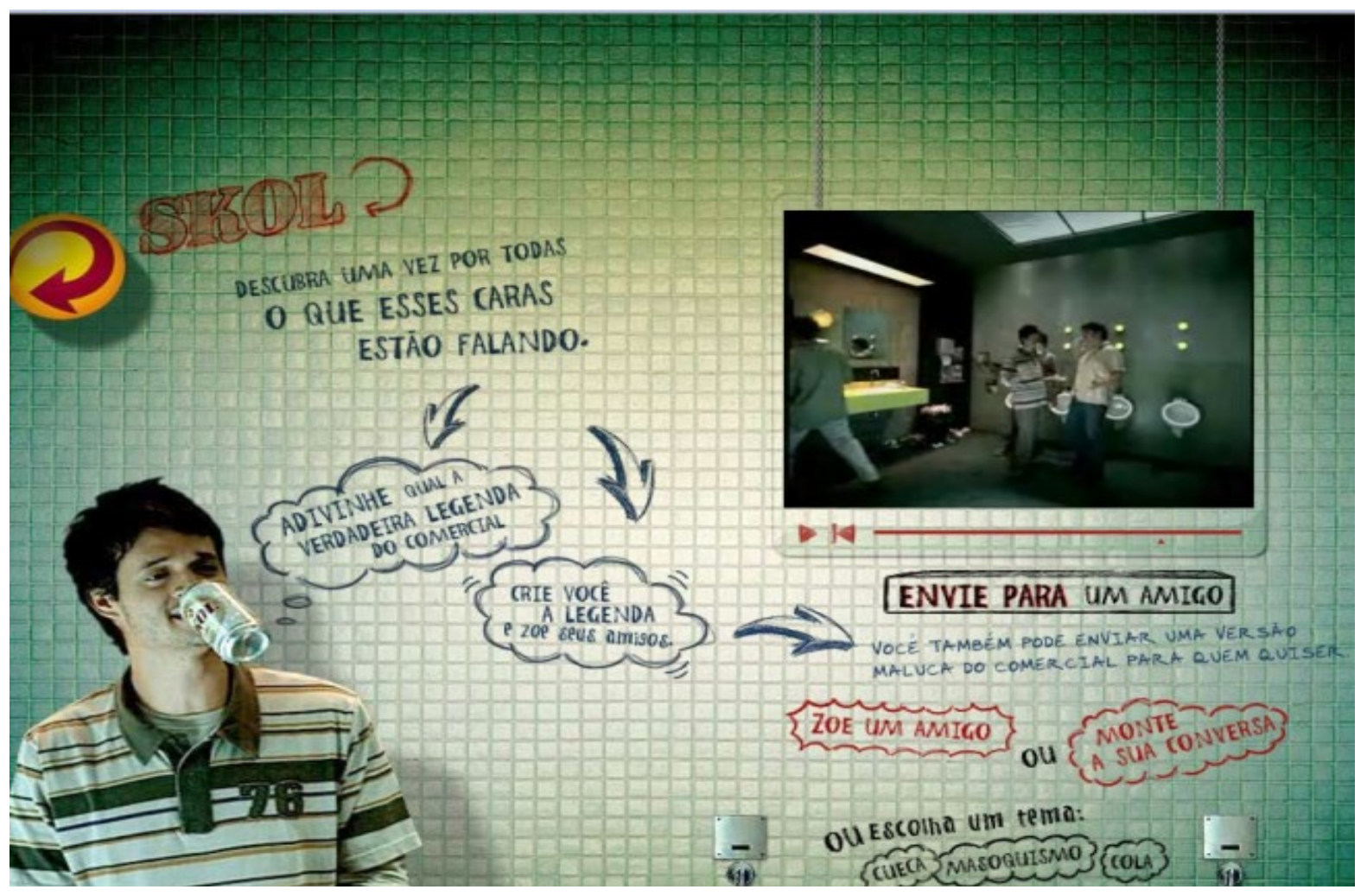

Figura 4: Hotsite Skol

Fonte: Disponível em http://descubra.skol.com.br"11

Outro caso de sucesso e duradouro é o da campanha da Doritos Crash the Super Bow ${ }^{\prime 2}$. Nela, o consumidor é convidado a criar um comercial para o produto, e a grande recompensa é que o eleito por votação dos usuários no site da campanha é veiculado no intervalo do Super Bowl, a final do campeonato de futebol americano dos Estados Unidos, considerado o break comercial mais caro do mundo, tendo custado em torno de 4 milhões de dólares na edição de $2013^{13}$ e podendo ser assistido por mais de 100 milhões de pessoas. A primeira edição do Crash the Super Bowl foi em 2007, quando dois jovens americanos de 21 e 22 anos venceram a disputa com um orçamento

11 Acesso em: 13 nov. 2011.

12 Disponível em http://www.crashthesuperbowl.com.

13 Disponível em http://goo.gl/QsMib. Acesso em: 20 maio 2013. 
de produção de U\$ 12,00. O vídeo não possui uma grande produção, mas sim bom humor ao narrar uma história em que um casal perde a atenção por causa do outro e também pelo pacote de Doritos que eles tem na mão.

A Doritos não foi a primeira marca a utilizar a participação do usuário para seus comerciais veiculados no Super Bowl. Em 2006, a Chevrolet já havia feito um concurso com estudantes universitários para a criação do comercial da marca Chevy, quando mais de 400 equipes e 800 estudantes americanos participaram. A diferença aqui reside no fato que os conceitos foram apresentados para executivos da empresa, na cidade de Detroit, os quais selecionaram a melhor para ser produzida pela sua agência de publicidade. Os ganhadores ainda puderam participar de toda a produção do comercial.

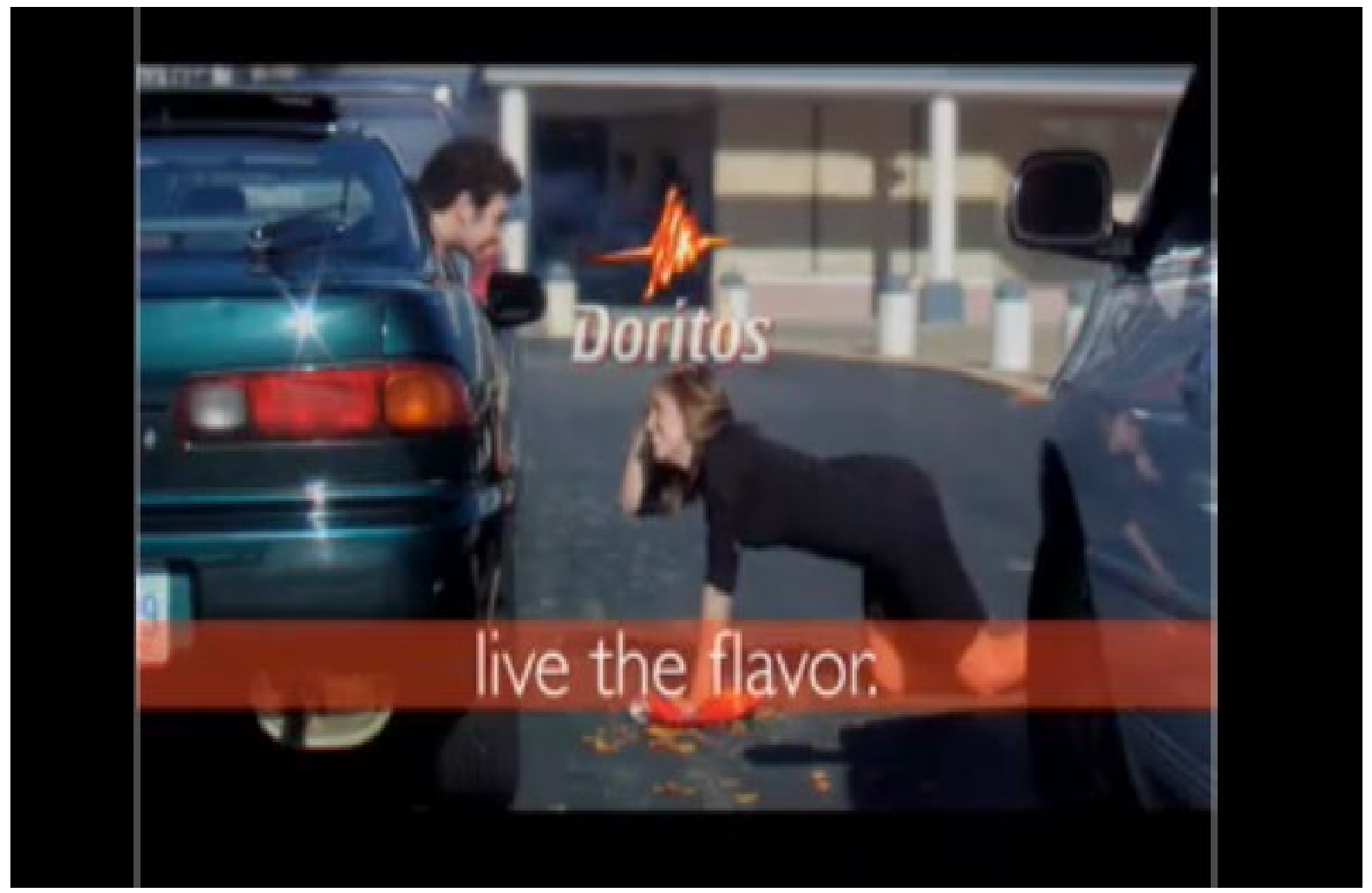

Figura 5: Doritos Live The Flavor

Fonte: Disponível em http://goo.gl/Z6Z7 ${ }^{14}$

Nick Haley era um estudante inglês como qualquer outro com 18 anos de idade, até o dia em que resolveu disponibilizar no YouTube um comercial de sua autoria do iPod Touch, em outubro de 2007. Baseado em outros comerciais do iPod Touch e elementos adquiridos do próprio site da Apple, Nick criou em seu MacBook um vídeo com a mesma linguagem e linha criati-

14 Acesso em: 20 maio 2013. 
va utilizada pela Apple. Dessa forma, a empresa tomou conhecimento do vídeo e entrou em contato com o jovem, oferecendo, através de sua agência de publicidade, uma proposta para utilizar sua criação, desta vez produzida com uma qualidade superior, sem mudar nada além da qualidade, como o comercial do novo iPod Touch. No início Nick não acreditou, mas depois retornou o contato e foi até a sede da agência TBWA, em Los Angeles, para acompanhar a produção de seu vídeo. O comercial foi veiculado em horário nobre nos Estados Unidos, Europa e Japão.

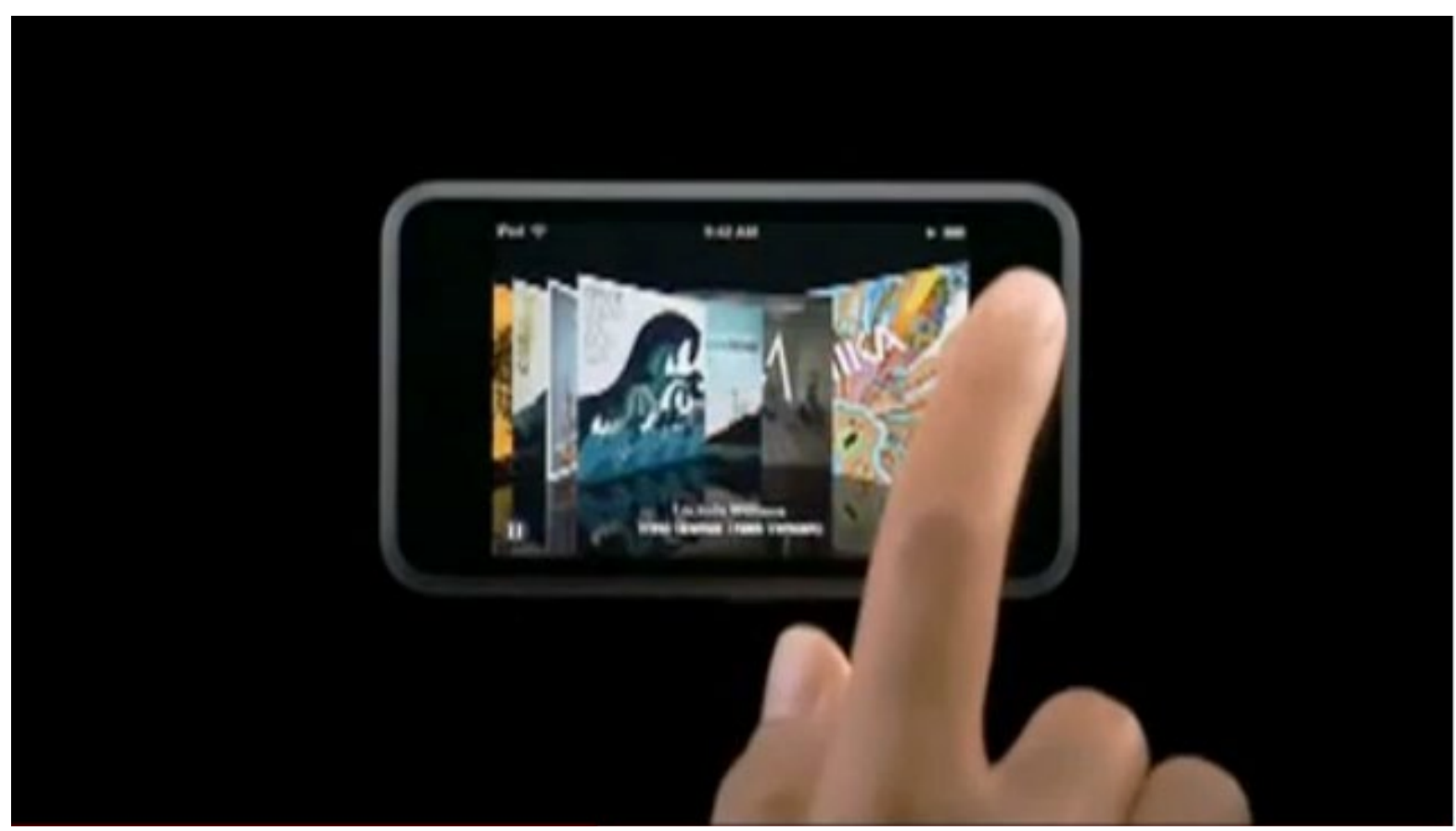

Figura 6: Comercial de Nick Haley para o iPod Touch Fonte: http://goo.gl/zPU3 ${ }^{15}$

\section{CONSIDERAÇÕES FINAIS}

Com os exemplos citados, pode-se constatar a presença dos avanços tecnológicos e sua facilidade de acesso pelos usuários, o que faz com que aumente sua participação e colaboração, criando relações sociais em torno de interesses comuns (LEMOS, 2004). Assim, segundo Lévy (1998), os grupos sociais advindos dessas relações são mais inteligentes que os indivíduos que os compõem. Dessa forma, a participação não reside apenas nessas criações, mas também no fato dos usuários repassarem as obras para suas redes virtuais, sejam elas de amigos, interesses comuns, trabalho, estudos, etc., exponencializando o número de pessoas expostas a elas. Pois, para

15 Acesso em: 20 maio 2013. 
Castells (1999), o que importa não é a centralização do conhecimento, mas sim o as diversas formas possíveis do uso das tecnologias disponíveis. É a cultura do "do it yourself" (faça você mesmo) que toma conta do cotidiano das pessoas, consequência do processo liberador da web 2.0, em que liberta-se o polo emissor, dando voz a todo e qualquer usuário (LEMOS, 2004).

Pode-se considerar que existem duas formas de publicidade colaborativa: uma, onde marcas e empresas fazem suas solicitações para consumidores ou usuários, e outra em que os próprios usuários criam por vontade própria. No primeiro tipo, nada impede que seja feita uma comparação ao tradicional processo publicitário. Nele, de uma forma geral e resumida, o cliente (empresa) vai até a agência solicitar um trabalho. Feito o trabalho, ele é apresentado ao cliente, que poderá aprovar ou não, de acordo com sua análise (GOMES, 2003). Nesse tipo de publicidade colaborativa, a internet faria o papel da agência, de mediação entre o cliente e a equipe criativa. Esta, por sua vez, fica por conta dos inúmeros usuários interessados em colaborar e participar das solicitações propostas por marcas e empresas, e não apenas ao departamento de criação de uma agência. É como se a agência terceirizasse esse procedimento.

De outro lado, existem os usuários que realizam suas criações por livre iniciativa, seja para demonstrar sua aprovação à marca, seja para provar suas habilidades em lidar com as ferramentas tecnológicas, ou seja ainda apenas pela simples realização enquanto criador de uma peça publicitária. Não importa o motivo, o interessante é mostrar sua opinião e suas capacidades. Os outros usuários da rede devem ficar sabendo. Debord já afirmava, na sua sociedade do espetáculo (1997), que as relações sociais entre as pessoas são mediadas por imagens, o que acarreta numa total espetacularização do mundo, com a criação em massa de novas personalidades e subjetividades a qualquer momento, novas imagens de si, representadas aqui pelas obras criativas produzidas, para serem mostradas aos outros.

\section{REFERÊNCIAS}

CASTELLS, Manuel. A era da informação: economia, sociedade e cultura. São Paulo: Paz e Terra, 1999.

DEBORD, Guy. A sociedade do espetáculo. Rio de Janeiro: Contraponto, 1997.

FELINTO, Erick. VIDEOTRASH: O YouTube a cultura do "spoof" na internet. In: XVI Encontro da Compós. Curitiba: 2007.

FRITO LAY. DORITOS ${ }^{\circledast}$ Surprises Super Bowl Television Audience Airing Two Consumer- 
-Created Commercials; 'Live The Flavor' and 'Check Out Girl. 4 fev. 2007. Disponível em: http://www.fritolay.com/about-us/press-release-20070204a.html. Acesso em: 30 jul. 2012.

GANG. Sobre a Gang. A loja que te entende. 2010. Disponível em: http://www.gang.com. br/geral/sobre.asp. Acesso em: 23 jun. 2010.

GOMES, Neusa Demartini. Publicidade: comunicação persuasiva. Porto Alegre: Sulina, 2003.

HOWE, Jeff. Crowdsourcing: why the power of the crowd is driving the future of business. New York: Crown Business, 2008.

JENKINS, Henry. Cultura da convergência. Tradução de Susana Alexandria. São Paulo: Aleph, 2008.

LEMOS, André. Cibercultura: tecnologia e vida social na cultura contemporânea. Porto Alegre: Sulina, 2004.

LÉVY, Pierre. A inteligência coletiva: por uma antropologia do ciberespaço. Edições Loyola: São Paulo, 1998.

MANOVICH, Lev. New Media and Remix Culture (introduction to Korean edition of LNM). 2003. Disponível em: http://www.manovich.net/DOCS/LNM_Korea_intro.pdf. Acesso em: 30 jul. 2012.

, Lev. Software takes command. 2008. Disponível em: http://softwarestu-

dies.com/softbook/manovich_softbook_11_20_2008.pdf. Acesso em: 30 jul. 2012.

TAPSCOTT, Don; WILLIAMS, Anthony. Wikinomics: como a colaboração em massa pode mudar o seu negócio. Tradução de Marcello Lino. Rio de Janeiro: Nova Fronteira, 2007.

TIME. Time's Person of the Year: You. Revista Time, 2006. Disponível em: http://www. time.com/time/magazine/article/0,9171,1569514,00.html. Acesso em: 30 jul. 2012.

VICKERY, Graham; WUNSCH-VINCENT, Sacha. Participative web and user-created content: web 2.0, wikis and social network. Paris: OECD, 2007.

WHITLA, Paul. Crowdsourcing and its application in marketing activities. Contemporary Management Research, Taipei, v. 5, n. 1, p. 15-28, março de 2009. 


\section{Lúcio Siqueira Amaral Filho}

Publicitário (UFSM), Mestre em Comunicação e Linguagens (UTP), Doutorando em Ciências da Comunicação (Unisinos) e integrante do Grupo de Pesquisa Audiovisualidades e Tecnocultura: comunicação, memória e design (Unisinos). Atualmente é professor do curso de Publicidade e Propaganda da ESPM Sul e do curso técnico de Publicidade da Ftec Porto Alegre.E-mail: lucio@lucioamaral.com.br. 